\title{
Assessment of blinding may be inappropriate after the trial [Letter to the Editor]
}

\author{
Hemilä $\mathbf{H}$ \\ Contemporary Clinical Trials 2005; 26:513-5
}

Published version: http://dx.doi.org/10.1016/j.cct.2005.04.002

\section{Pre-print version of the manuscript}

\author{
Harri Hemilä, $\mathrm{PhD}, \mathrm{MD}$ \\ Department of Public Health, \\ POB 41, University of Helsinki, \\ Helsinki, FIN-00014 Finland \\ harri.hemila@helsinki.fi \\ http://www.ltdk.helsinki.fi/users/hemila
}

In their paper discussing the assessment of blinding in clinical trials, Bang et al. [1] based their analysis on the premise that "all participants randomly guess their assignment ... This is the most ideal scenario in reality" [ref. 1, p. 149]. However, this premise makes an implicit assumption that the drug does not differ from placebo in any physiological effects that a person could observe subjectively, which is a very strong assumption. If a drug is truly effective, such as penicillin for pneumococcal pneumonia, both the patient and the physician can infer the treatment with high certainly by subjective observations. Thus, when the drug is truly effective, we are expecting "breaking of blindness."

Bang et al. [1] admit in their discussion, that "it is possible that unsuccessful blindness may not influence statistical analysis in the end." Thereafter they state that "in a well-known trial of vitamin C, the perceptions affected the endpoint concerning cold symptoms," thus providing the Karlowski et al. [2] trial as the single example of a trial in which breaking of blindness may have caused the observed difference between the study arms.

The Karlowski trial was planned as a double-blind placebo-controlled trial. Because of the shortage of time, no appropriate placebo (e.g. citric acid) was manufactured, and they used lactose-placebo which is sweet and differs in taste from vitamin C (ascorbic acid). At the end of the trial many participants guessed correctly their treatment, and this led Karlowski to carry out a subgroup analysis by the blindness status of the participants. Vitamin C appeared effective among "unblinded" participants, but no effect was seen among "blinded" participants [2,3]. This subgroup finding was spectacular by indicating that knowledge of treatment explained the differences between the study arms. Therefore the Karlowski trial has been frequently cited as an example of the importance of blinding, e.g., in the CONSORT statement pointing out the importance of trial quality [4], and as the only example by Bang et al. [1].

However, the subgroup analysis by Karlowski et al. [2,3] is not valid. For example, a total of 249 common cold episodes were recorded in the trial, but the subgroup analysis contained only 144 episodes, so that 105 episodes ( $42 \%$ of all) were missing [5]. Karlowski did not mention the exclusion of 105 episodes from their subgroup analysis, nor did they present their rationalization for the greater than average benefit (sic!) in the excluded participants who were neither "blinded" nor "unblinded" [5]. Further problems of the "placebo effect explanation" are detailed elsewhere [5]. Chalmers, the principal author, commented on the re-analysis of the Karlowski trial [6], but his criticism appears to be invalid [7].

Vitamin $\mathrm{C}$ has consistently reduced the duration and severity of colds $[8,9]$, and some of the largest trials explicitly reported that vitamin C and placebo tablets looked and tasted the same [10-12]. The validity of the placebo should be determined before the trial. Blindness at the end of the trial may be influenced by the true physiological effects of the drug [5]. 


\section{References}

[1] Bang H, Ni L, Davis CE. Assessment of blinding in clinical trials. Cont Clin Trials 2004;25:143156. http://dx.doi.org/10.1016/j.cct.2003.10.016

[2] Karlowski TR, Chalmers TC, Frenkel LD, et al.. Ascorbic acid for the common cold. A prophylactic and therapeutic trial. JAMA 1975;231:1038-1042.

http://dx.doi.org/10.1001/jama.231.10.1038

[3] Lewis TL, Karlowski TR, Kapikian AZ, et al. A controlled clinical trial of ascorbic acid for the common cold. Ann NY Acad Sci 1975;258:505-512.

[4] Begg C, Cho M, Eastwood S, et al. Improving the quality of reporting of randomized controlled trials. The CONSORT statement. JAMA 1996;276:637-639.

http://dx.doi.org/10.1001/jama.276.8.637

[5] Hemilä H. Vitamin C, the placebo effect, and the common cold: a case study of how preconceptions influence the analysis of results. J Clin Epidemiol 1996;49:1079-1084.

http://dx.doi.org/10.1016/0895-4356(96)00189-8

[6] Chalmers TC. To the preceding article by H. Hemilä. J Clin Epidemiol 1996;49:1085. http://dx.doi.org/10.1016/0895-4356(96)00190-4

[7] Hemilä H. To the dissent by Thomas Chalmers. J Clin Epidemiol 1996;49:1087. http://dx.doi.org/10.1016/0895-4356(96)00191-6

[8] Hemilä H. Vitamin C, respiratory infections and the immune system. Trends Immunol 2003;24:579-80. http://dx.doi.org/10.1016/j.it.2003.09.004

[9] Douglas RM, Hemila H, D'Souza R, Chalker EB, Treacy B. Vitamin C for preventing and treating the common cold (Cochrane Review). In: The Cochrane Library, Issue 4, 2004. http://www.cochrane.org/reviews/en/ab000980.html

Entire text freely available (version 2004): http://medicine.plosjournals.org/archive/1549-1676/2/6/supinfo/10.1371_journal.pmed.0020168.sd001.pdf

[10] Anderson TW, Reid DBW, Beaton GH. Vitamin C and the common cold: a double-blind trial [published erratum: 1973;108:133]. Can Med Assoc J 1972;107:503-508.

http://www.pubmedcentral.nih.gov/articlerender.fcgi?tool=pmcentrez\&artid=1940935 http://www.pubmedcentral.nih.gov/articlerender.fcgi?tool=pmcentrez\&artid=1941144

[11] Pitt HA, Costrini AM. Vitamin C prophylaxis in marine recruits. JAMA 1979;241:908-911. http://dx.doi.org/10.1001/jama.241.9.908

[12] Ludvigsson J, Hansson LO, Tibbling G. Vitamin C as a preventive medicine against common colds in children. Scand J Infect Dis 1977;9:91-98.

http://www.ltdk.helsinki.fi/users/hemila/CC/Ludvigsson_1977_ch.pdf 